\title{
A hexis educativa como possibilidade pedagógica em narrativas ficcionais para jovens.
}

\author{
Milena de Azeredo Pacheco Venancio \\ Universidade Federal Fluminense
}

Alexandre Farbiarz

Universidade Federal Fluminense

\begin{abstract}
Resumo
O artigo proposto busca refletir sobre o conceito de hexis educativa, para compreender o potencial pedagógico de narrativas ficcionais para jovens, sendo o estudo de caso a série "Harry Potter". A discussão será articulada com a questão do preconceito como elemento do cotidiano para compreender o indivíduo em sua relação com o outro, a partir do conceito de alteridade. Para tal, será feita análise Sociolinguística Interacional de alguns elementos constitutivos da obra.
\end{abstract}

Palavras Chave: Hexis Educativa, Alteridade, Preconceito, Harry Potter.

\begin{abstract}
This article seeks to reflect on the concept of educational hexis to understand a pedagogical potential in fictional narratives for young people, using the Harry Potter series as an example. The discussion is articulated with the question of prejudice as an everyday element in order to understand the individual in relation to the other, based on the concept of otherness. For this purpose, an Interactional Sociolinguistics analysis will be made of Harry Potter's narrative.
\end{abstract}

Keywords: Educative Hexis, otherness, prejudice, Harry Potter

\section{INTRODUÇÃO}

Na vida cotidiana, lidar com as diferenças é uma situação constante. Porém, o preconceito e a intolerância às diferenças se fazem presentes. Tal choque perante a diversidade permite refletir sobre as relações sociais do indivíduo com toda a heterogeneidade que compõe o cotidiano. Segundo Heller (2000, p. 20), “a vida cotidiana é a vida do indivíduo”, logo, não há como se explicar o homem sem perceber a diversidade que o caracteriza.

O indivíduo é sempre, simultaneamente, ser particular e ser genérico. Considerado em sentido naturalista, isso não o distingue de nenhum outro ser vivo. Mas, no caso do homem, a particularidade expressa não apenas seu ser ‘isolado', mas também seu ser 'individual'. Basta uma folha de árvore para 
lermos nela as propriedades essenciais de todas as folhas pertencentes ao mesmo gênero; mas um homem não pode jamais representar ou expressar a essência da humanidade. (Ibid., p. 20)

Assim, seria paradoxal a não aceitação das diferenças, visto que todo indivíduo é, essencialmente, diferente de outro. A não aceitação das diferenças pode ser pensada a partir do que expõe Arendt (2007) sobre o indivíduo se manifestar para o outro através de sua diferença em relação aos demais, mas ser definido por este a partir do que tem em comum. Assim, a diferença acaba por ser negada nas relações humanas.

Porém, visto que o indivíduo é ser particular e genérico, se formando em meio à coletividade, a relação com o outro é fator determinante na formação da sua identidade. Segundo Ricoeur e Arendt, apud Conceição e Amitrano (2011, p. 1) “qualquer postura do sujeito no mundo e diante de si é comprometimento, é ação ética, é identidade. E o outro é condição sine qua non da identidade do sujeito”. Nesse sentido, entender a relação do sujeito com os demais indivíduos ${ }^{1}$ pode auxiliar na compreensão de como esse sujeito se situa no mundo. Partindo do que diz Barbosa (2007, p. 13) à luz de Ricouer ${ }^{2}$ (1987), que "narrar é uma forma de estar no mundo e dessa forma entendê-lo”, tudo o que o sujeito propõe em sua presença no mundo é narrativa.

Logo, através do contato do indivíduo com diferentes narrativas, podem ser enunciadas possibilidades de reflexão sobre as relações entre os diferentes indivíduos e o papel atribuído a cada um em sua presença no mundo, levando-o a pensar sobre a questão da alteridade e as problemáticas que dela decorrem, como é o caso das relações de preconceito. Visto que, segundo Sodré (2013, p. 86) “educar equivale a iniciar a consciência na trilha de um estranhamento interno e externo (o 'amável estrangeiro’ pensado por Rosseau), que significa a possibilidade de pensar”, o contato com diferentes narrativas poderia, então, atuar de uma forma educativa ao incitar a reflexão a partir do estranhamento e a tomada de consciência.

\footnotetext{
${ }^{1}$ Apesar de existirem diferenças conceituais entre os termos “sujeito” e “indivíduo”, este artigo utilizará os termos no sentido amplo das palavras, não fazendo parte de seu escopo adentrar as discussões sobre as distinções entre eles e suas especificidades. Considera-se esta utilização dos termos possível, visto que suas definições não necessariamente se excluem, mas se complementam. Segundo Morin (1999, n. p.), por exemplo, “de uma forma mais profunda e básica, a autonomia do indivíduo vivo - em especial o humano — se afirma em sua condição de sujeito”.

${ }^{2}$ RICOEUR, Paul. De l'interprétation. Paris: PUF, 1987.
} 
O estranhamento pode se dar pela consciência do indivíduo, ou seja, internamente, bem como por sua visão de mundo, logo, externamente. E se o outro contribui para a construção narrativa do indivíduo, o pensamento acerca deste outro se reflete tanto na narrativa histórica quanto na ficcional, visto que, de acordo com Barbosa (2007), ainda à luz de Ricoeur, a ficção, assim como a história, tem como base a temporalidade da experiência humana. Nesse sentido, as narrativas presentes na produção midiática, dada a pluralidade da audiência que podem alcançar em diferentes mídias, enunciam possibilidades de abertura ao diferente, caso tenham uma abordagem junto ao público que apresente relações de alteridade que o leve à reflexão.

Interessa, portanto, discutir como a abordagem das relações de alteridade e preconceito em narrativas ficcionais infanto-juvenis pode propiciar uma prática educativa que leve à reflexão desta temática. Para tal, será desenvolvido nesse texto o conceito de hexis educativa proposto por Sodré (2013), utilizado como base para um estudo de caso da série Harry Potter, uma vez que há nela presença marcante dos temas em discussão, bem como em razão do impacto cultural e midiático da obra.

Assim, o pressuposto da pesquisa é que a série Harry Potter é um exemplo que enuncia a reflexão sobre o preconceito em narrativas ficcionais infanto-juvenis. Busca-se compreender, portanto, como determinados elementos constitutivos da série enunciam uma hexis educativa junto ao público de narrativas ficcionais infantojuvenis, especialmente em relação a questões acerca do preconceito, a partir da perspectiva das relações de alteridade e identidade.

\section{PERSPECTIVA SOBRE IDENTIDADE E PRECONCEITO EM HARRY POTTER}

Na história apresentada na obra Harry Potter, remetendo a preconceitos vigentes na sociedade, a narrativa aborda choques culturais que, na estrutura ficcional, acabam por levar à reflexão de questões que se apresentam no cotidiano. A narrativa, principalmente na fala e nas ações dos protagonistas ao longo de toda a trama, destaca a importância de saber lidar com as diferenças e não julgar previamente o outro. Partindo deste princípio, há uma problemática constante no enredo: a contraposição entre o comportamento dos personagens que aceitam as diferenças e aqueles que buscam manter o status quo, com todas as barreiras que tal situação impõe às relações de alteridade. 
Tal relação se desenvolve ao longo da narrativa em diversas relações de preconceito, o que já levou a obra a ser estudada sob esta perspectiva. Segundo estudo publicado no Journal of Applied Social Psychology ${ }^{3}$ (2015), feito a partir dos livros e filmes de J. K. Rowling, verificou-se maior tolerância em relação a determinados estratos sociais considerados minoritários, especificamente imigrantes, homossexuais ${ }^{4}$ e refugiados, a partir do contato com a história (VEZZALI et al, 2015).

O estudo partia da hipótese de que a exposição a elementos midiáticos apresenta resultados cognitivos e afetivos similares aos efeitos de experiências diretas em diferentes contextos (ORTIZ e HARWOOD ${ }^{5}$, 2007, apud VEZALLI et al, 2015). Assim, em articulação com a teoria social cognitiva (BANDURA, $1997^{6}$ e $2002^{7}$, apud VEZALLI et al, 2015) foram realizados três experimentos que discutiam passagens da história de Harry Potter: um experimento com jovens italianos do ensino fundamental que abordava questões sobre imigrantes, um segundo experimento com jovens italianos do ensino médio e com o direcionamento das discussões para a questão dos homossexuais e, por fim, um terceiro experimento com estudantes de graduação ingleses, que abordava tanto questões em geral quanto questões específicas em relação a refugiados.

No caso, o foco foi estudar o preconceito em relação a imigrantes, homossexuais e refugiados, uma vez que é o mais presente em países da Europa, segundo os estudos prévios utilizados pelos pesquisadores (PEREIRA, VALA e

\footnotetext{
${ }^{3}$ Vários veículos de comunicação também divulgaram informações sobre o trabalho, como a Revista Galileu (disponível em: <http://revistagalileu.globo.com/Ciencia/Psicologia/noticia/2014/07/ler-harrypotter-ensina-criancas-lutar-contra-o-preconceito1.html>), Pacific Standard (disponível em: <http://www.psmag.com/books-and-culture/harry-potter-battle-bigotry-87002>) e Scientific American (disponível em: <http://www.scientificamerican.com/article/why-everyone-should-read-harrypotter/>). Acesso em: 24 jul. 2015.

${ }^{4}$ Embora haja uma discussão acerca do uso do termo "homossexual”, muitas vezes sendo sugerido o termo "homoafetivo" em seu lugar, não se entrará nesta questão, uma vez que isso demandaria outros estudos paralelos, o que não é o foco deste trabalho. Se manterá, portanto, o uso da palavra "homossexual” neste texto, considerando-a equivalente a "homoafetivo”, visto ser a tradução literal da palavra no texto original ao qual se faz referência.
}

${ }^{5}$ ORTIZ, M.; HARWOOD, J. A social cognitive theory approach to the effect of mediated intergroup contact on intergroup attitudes. In: Journal of broadcasting and electronic media. n. 51. [S. 1.]: Routledge, 2007.

${ }^{6}$ BANDURA, A. Self-efficacy: the exercise of control. Nova York: Freeman, 1997.

${ }^{7}$ BANDURA, A. Social congnitive theory of mass communication. In: J. Bryant; D. Zilmann (Orgs.).

Media effects: advances in theory and research. Hillsdale: Erlbaum, 2002. 
COSTA-LOPEZ, 2010 ${ }^{8}$; SCHMID et al, 2012 ${ }^{9}$; WEST e HEWSTONE, $2012^{10}$; ZICK, PETIGREW e WAGNER, $2008^{11}$, apud VEZZALI et al, 2015). Porém, podese considerar que tais questões são inerentes ao ser humano, independente de sua nacionalidade e, visto que o preconceito a qualquer grupo pressupõe um rebaixamento do outro, os resultados podem ser considerados em pesquisas feitas fora desses países e no que diz respeito ao preconceito a outros grupos que não os citados.

Os estudos também levaram em consideração outros trabalhos que demonstrassem a riqueza de tópicos abordados na história, como o artigo Playing the genre game: generic fusions of the Harry Potter series (ALTON, $2009^{12}$ apud VEZZALI et al, 2015), e o fato de Harry Potter mostrar uma estrutura social em que conflitos entre diferentes grupos são tópicos importantes no enredo, tema do texto Intergroup conflict in the world of Harry Potter (BEERS e APPLE, $2006^{13}$, apud VEZZALI et al, 2015).

O fato de vários trabalhos que abordam a obra Harry Potter serem utilizados como base teórica para o estudo publicado no Journal of Applied Social Psychlogy, demonstra que há interesse sobre as questões apresentadas na obra acerca do preconceito e como estas se desenvolvem junto ao público em idade escolar. Nesse sentido, o uso dos livros e filmes da série Harry Potter se torna uma possibilidade educativa na discussão sobre o preconceito junto a jovens fãs da obra.

Ressalta-se que, por se tratar de uma história originalmente lançada como livro, a palavra tem papel fundamental na construção das reflexões sobre alteridade e

\footnotetext{
${ }^{8}$ PEREIRA, C.; VALA, J.; COSTA-LOPEZ, R. From prejudice to discrimination: the legitimizing role of perceived threat in discrimination against immigrants. In: European Journal of Social Psychology. n. 40. Nova York: John Wiley \& Sons: 2010.

${ }^{9}$ SCHMID, K. et al. Secondary transfer effects of intergroup contact: a cross-national comparison in Europe. In: Social Psychology Quartely. n. 75. [S. 1.]: SAGE Publishing, 2012.

${ }^{10}$ WEST, K.; HEWSTONE, M. Relatively socially acceptable prejudice within and between societies. In: Journal of Community and Applied Social Psychology. n. 22. Nova York: John Wiley \& Sons, 2012.

11 ZICK, A.; PETTIGREW, J. F.; Wagner, U. Ethnic prejudice and discrimination in Europe. In: Journal of Social Issues. n. 64. Nova York: John Wiley \& Sons, 2008.

${ }^{12}$ ALTON, Annie Hiebert. Playing the genre game: Generic fusions of the Harry Potter series. In: HEILMAN, Elizabeth E. (Org.) Critical perspectives on Harry Potter. 2 ed. Nova York: Routledge, 2009.

${ }^{13}$ BEERS, Melissa. J.; APPLE, Kevin J. Intergroup conflict in the world of Harry Potter. In: MUlHOLland, Neil (Org.) The psychology of Harry Potter: An Unauthorized Examination Of The Boy Who Lived. Dallas: BenBella Books, 2006.
} 
preconceito nos discursos dos personagens. Nota-se, na metáfora utilizada na narrativa de Harry Potter, o pensamento de Bakhtin (2006), quando afirma que a palavra é constituída tanto pela interação entre locutor e interlocutor quanto na expressão de um em relação ao outro, posicionando-se, assim, em relação à diversidade.

No caso da narrativa da série, através da diversidade apresentada, é estabelecido o diálogo entre os personagens que, em suas relações, trazem à tona diversas questões, em especial, no contexto da relação com o outro e do preconceito. Surgem discussões sobre o racismo, através da busca pelo domínio dos bruxos de “sangue puro" sobre os que possuem ascendência "trouxa”"14, representada principalmente pelo vilão da história, Lord Voldemort; preconceito social, com as humilhações sofridas pelo personagem Rony; sentimentos de medo e curiosidade despertados pela própria presença de Harry Potter entre os colegas, por ser sobrevivente de um ataque que, em circunstâncias normais, nenhum bruxo sobreviveria; além de outros elementos constitutivos do enredo que determinam um eixo narrativo em torno da aceitação do outro.

Na obra, são marcantes as analogias com situações vividas no cotidiano que se dão a partir de dois fatores em especial: identidade e preconceito. Segundo Heller (2000), os juízos provisórios podem levar ao preconceito, embora não sejam a única condição para tal. Estes juízos provisórios, quando apresentassem como correta uma ideia que não fosse verdadeira, poderiam ser corrigidos mediante a experiência, o pensamento, o conhecimento e a decisão moral individual.

Assim, podemos dizer que o preconceito é um saber sobre algo sem o devido conhecimento. Em uma fala sobre a diversidade, Sodré (2011) afirma que “o preconceito é o saber automático sobre o outro”. Sendo assim, há uma comparação que não produz informação relevante sobre o conhecimento acerca do outro, mas permitiria que aquele que faz a comparação se sobrevalorize e rebaixe aquele que é comparado.

Pode-se dizer que aí está a raiz da intolerância quanto ao diferente. No caso da trama de Harry Potter, uma das principais discussões que envolvem o preconceito é a de que quem não tem ascendência totalmente bruxa é considerado "sangue ruim”,

\footnotetext{
14 “Trouxa” é a tradução aplicada à palavra “muggle” que, nos livros e filmes da série, é utilizada para designar as pessoas que não possuem poderes mágicos, logo, não sendo consideradas de "sangue puro”.
} 
o que viria a ser a maior ofensa possível de se receber entre os bruxos. Nesse caso, rebaixa-se à condição de inferior a pessoa que sofre tal comparação com aqueles que são de família totalmente bruxa. Esse é o discurso dos chamados “Comensais da Morte”, bruxos que acompanham o vilão Lord Voldemort em sua busca pelo poder e eliminação de seres por eles entendidos como inferiores.

No entanto, como afirmar que no grupo dos que se consideram superiores há uma identificação entre iguais? Há de se considerar que mesmo dentro de um grupo com propósitos semelhantes, há diferenças. Sobre a questão da diferenciação, Hall (2006, p. 11) observa que “a identificação não é automática, mas pode ser ganhada ou perdida”.

Nesse sentido, o problema da diferenciação está no fato de que o senso comum pensa que a identidade está dada, não sabendo fazer a diferença (SODRÉ, 2011). Hall discorda deste pensamento, de que a identidade é imutável, quando afirma que:

\footnotetext{
A identidade plenamente unificada, completa, segura e coerente é uma fantasia. Ao invés disso, à medida em que os sistemas de significação e representação cultural se multiplicam, somos confrontados por uma multiplicidade desconcertante e cambiante de identidades possíveis, com cada uma das quais poderíamos nos identificar - ao menos temporariamente. (HALL, 2006, p. 13)
}

Logo, as múltiplas identidades com as quais o indivíduo se confronta, podem ser um choque para aquele que, de acordo com o senso comum, pensa ser a identidade algo dado e imutável. Considerando, assim, o que se apresenta a partir do senso comum, aquele que é considerado diferente em comparação a um determinado padrão, tende a permanecer isolado dos demais. O protagonista Harry Potter, muitas vezes, em função de sua singularidade, se encontra isolado do convívio de outros personagens, visto que passa por situações singulares às dos demais. Nestes momentos, somente os personagens que são efetivamente do seu círculo de amizades se mantém com ele. Tais personagens, aliás, são os que também sofrem alguma forma de preconceito ao longo do enredo: seja por ter baixo poder aquisitivo (Rony), seja por ser filha de “trouxas” (Hermione) ou por ser de família de gigantes (Hagrid).

A relação de um personagem com o outro, dentro deste círculo de amizade, é essencial para compreender a relação com o diferente e como a mesma pode se configurar, ou não, em preconceito. No caso, a relação entre os protagonistas na narrativa de Harry Potter está intrinsecamente ligada à compreensão do outro, o que é uma das bases para a tolerância ao diferente. 
Bakhtin (1997) explica, em seus estudos sobre a linguagem, que o outro é condição para a existência do discurso e para a própria compreensão que o indivíduo tem de si mesmo. E, retomando o dito por Sodré (2011) - de que o preconceito se caracteriza por um saber sobre o outro sem a devida reflexão -, para que o indivíduo se veja no outro, se nivelando a ele, o caminho de reflexão é bem mais complexo, pois, de acordo com as palavras de Bakhtin (1997, p. 76), "se quero operar uma transposição que nos coloque, eu e o outro, num único e mesmo nível, devo, em meus valores, situar-me fora da minha própria vida e perceber-me como outro entre os outros”. Logo, há a necessidade de uma ação que parta da própria consciência, e não do senso comum.

Na série Harry Potter, determinados personagens, detentores do discurso de preconceito, muitas vezes se valem de concepções prévias sobre o outro, de modo a rebaixá-lo. Ao mostrar tal relação, a história abre possibilidades para que seu público, a partir dos exemplos retratados na narrativa, faça a abstração necessária e perceba-se no outro, ao se identificar com este, compreendendo-o em sua diferença.

\section{A HEXIS EDUCATIVA E SEU POTENCIAL NA NARRATIVA}

A possibilidade educativa presente em Harry Potter pode ser vista como uma “pedagogia informal” (JENKINS, 2009), pela questão do letramento que o contato com a obra propicia. Nesse sentido, há, de fato, uma forte apropriação da série de livros e filmes pelos fãs no formato chamado de fanfiction, onde os fãs criam suas próprias histórias imaginadas a partir da narrativa original.

Letramento que, por si só, já provocou reações contrárias, visto que muitos conservadores entendem a pedagogia de uma forma bem diferente e defendem que deve haver um discernimento quanto às possíveis representações religiosas e, na visão de tais conservadores, até mesmo ocultistas, presentes em Harry Potter (JENKINS, 2009). O questionamento conservador apresentado põe em confronto a cultura participativa, que se cria a partir da difusão da obra, com dois fatores essenciais na formação das crianças que, segundo o próprio Jenkins, seriam a educação e a religião.

Os reformadores morais admitem que os livros de Harry Potter estão despertando o hábito da leitura e do aprendizado, mas ficam apreensivos quanto ao conteúdo ensinado às crianças. Alguns ativistas encaram os livros como um enfraquecimento da influência cristã, em favor de um novo espiritualismo global. (Ibid., p. 269) 
No momento em que conservadores acreditam que a obra passa para os jovens uma ideia moral errada, vale considerar que é uma percepção de moral dentro de padrões estabelecidos em seus grupos. Neste sentido, há um pensamento que parte do ethos, ou seja, uma “consciência viva do grupo que impõe o sentido de costume como maneira regular ou mecânica de agir” (SODRÉ, 2013, p. 84). No entanto, essa percepção pode se tornar problemática, pois pode servir a interesses íntegros ou a atos morais negativos, mas que tenham validade dentro de um determinado grupo.

Logo, um pensamento que parta de uma consciência, de sentir-se bem com determinada forma de pensar e de agir, se torna uma possibilidade educativa, retomando a fala de Sodré (2011) sobre o educar ser incitar no indivíduo a possibilidade de pensar. Afinal, quando o indivíduo enxerga em exemplos com os quais se identifique, a atitude correta a se tomar em relação a uma determinada questão, passa a agir mediante a reflexão provocada, e não mais somente para se enquadrar em uma determinação moral do grupo em que está inserido.

Assim, a partir do cenário que apresenta, a história de Harry Potter pode favorecer que o público, ao se identificar com os conflitos ali presentes, passe a refletir sobre suas ações na vida social, o que levaria então, a uma mudança de postura. A experiência estética tem seu valor, nesse sentido, ao produzir sentimentos no público, a partir de elementos técnicos e estéticos que a compõem (BRAGA, 2010 apud PORTO e GONÇALVES, 2013).

Em uma perspectiva comunicacional, tal pensamento reproduz uma dialética hexis versus ethos, apresentada por Sodré (2013, p. 84) na obra Antropológica do espelho, ao debater a hexis educativa. Nela, o autor define a hexis como "a possibilidade de instalação da diferença na imposição estaticamente identitária do ethos”. Sendo assim, verifica-se uma relação na trama de Harry Potter da postura de personagens que possuem uma maior abertura às diferenças, como resultado de atitude baseada na consciência e na responsabilidade de estarem agindo da forma correta, ainda que o sistema em que se inserem abrigue, muitas vezes, ideias e valores preconceituosos. Em contrapartida, há o pensamento representado pelos personagens ligados ao vilão da história, os quais, assim como o próprio, enunciam o preconceito contra o outro ao se negarem a aceitar alguém diferente do que consideram "sangue puro".

Formula-se, então, um cenário com personagens que partem de uma atitude baseada na hexis, e outros, baseada no ethos, quando este é utilizado em favor de atos 
morais negativos. Sodré (2013), ao elucidar a ação a partir da hexis, permite compreender, de forma análoga em Harry Potter, o que distingue o pensamento entre os personagens.

O sujeito se apropria dos costumes herdados e tradicionalmente reproduzidos (portanto, concretamente, na moral, socialmente condicionada e limitada) com a disposição voluntária e racional de praticar atos justos e equilibrados dirigidos para um bem, uma virtude, um dever-ser, ou seja, tudo que reforce a recomendação socrática de evitar a prática de ações com as quais não se possa conviver e assim ser capaz de ganhar um potencial de liberdade e criação. Satisfaz, desse modo, uma exigência propriamente ética que, embora não pertença nesses mesmos termos de realização de uma virtude aos quadros sociais da modernidade hegemônica, vem-se mantendo através dos tempos. (Ibid., p. 84)

Assim sendo, a hexis pode ser considerada como uma possibilidade educativa a partir da formação de consciência no indivíduo sobre as consequências de suas escolhas. Nesse caso, portanto, as decisões são tomadas em função de um sentir-se bem consigo mesmo, e não por uma imposição moral estabelecida pelo grupo social no qual a pessoa está inserida. No caso de Harry Potter, essa hexis se expressa na atitude dos personagens que aceitam as diferenças. Do mesmo modo, uma vez que haja identificação com tais personagens pelo público, isto se desdobra em uma atitude mais tolerante do próprio público para com o diferente.

Sodré (2013) utiliza um exemplo interessante para uma melhor compreensão da hexis educativa. O autor cita histórias de Chuang-Tzu e Eugen Herrigel que tratam da relação do arqueiro com sua arte: o arco e a flecha. Nessas narrativas, apresenta-se o arqueiro como mais do que mero produto da aptidão, do treinamento e da técnica, mas alguém que transcenda estas características, agindo "guiado por uma razão de ser necessária e compatível com os destinos da comunidade humana” (Ibid., p. 84). Assim, se ultrapassaria a ethos, pressupondo a existência de uma hexis. Essa atitude é que resolveria a hexis, então, em educação, pois educar seria ir além da mera repetição de um costume determinado, aceitando os impulsos de liberdade que fazem o indivíduo passar do ethos para a hexis.

Assim se configuraria a hexis educativa, presente em Harry Potter, que leva à identificação do público com a obra, e assim, a uma atitude de tolerância junto ao outro, se posicionando contra preconceitos. Provoca-se o estranhamento quanto ao que é errado de se fazer ante uma determinada situação, entendendo que é necessário ir além da imposição da estrutura social em que o indivíduo está inserido, questionando os valores ali determinados quando desrespeitarem o outro, tal como é a postura dos principais personagens da história. 


\section{EXEMPLO DA INTERAÇÃO ENTRE PERSONAGENS DE HARRY POTTER}

Para uma melhor compreensão de como determinados elementos constitutivos da série Harry Potter enunciam uma hexis educativa acerca de questões relacionadas ao preconceito, será utilizado como exemplo um diálogo que demonstre que as situações vividas pelos personagens são análogas a situações de preconceito da vida cotidiana. Para tal, será utilizada a análise com base na Sociolinguística Interacional.

Um princípio básico da Sociolinguística Interacional é que a interação face a face tem sua complexidade enquanto cenário de construção de significado social. O importante nessa interação é que o agrupamento de pessoas em si não basta para que ocorra o comprometimento do encontro entre essas pessoas. No encontro, há uma orientação de um indivíduo para o outro que os separa dos demais indivíduos no agrupamento, formando o que seria, de fato, o encontro.

Há uma preferência por uma abertura mútua a toda maneira de comunicação. Há
tipicamente também uma aproximação física, um amontoado ecológico dentro
do qual os participantes se orientam na direção um do outro e se desviam
daqueles que estão presentes na situação mas que não estão oficialmente no
encontro. Há regras claras para o início e o término de encontros, para a entrada
e a saída de certos participantes em particular, para as exigências que um
encontro pode requerer de seus sustentadores e para o decoro de espaço e som
que deve ser observado em função dos participantes excluídos mas presentes à
situação. (GOFFMAN, 2013, p. 18)

Esses encontros são analisados na interação entre os personagens de Harry Potter, de modo a verificar como o preconceito se mostra em tais interações, a partir das falas dos personagens. A vantagem em se utilizar a Sociolinguística Interacional está na sua aplicabilidade a variadas formas de interação social.

Os trabalhos desenvolvidos nessa área [sociolinguística interacional] variam de acordo com o interesse do pesquisador, que poderá dar maior ou menor atenção ao fenômeno linguístico versus o fenômeno interacional. (TANNEN, apud RIBEIRO e GARCEZ, 2013, p.8)

Será dada maior atenção ao fenômeno interacional, de modo a compreender o objeto de pesquisa com base nas relações de alteridade enunciadas pelos personagens. Será utilizado um exemplo presente no livro Harry Potter e a câmara secreta, que demonstra o preconceito que parte do personagem Draco em relação à condição financeira do personagem Rony, e à origem “trouxa” da personagem Hermione. 


\section{Fortuna da obra Harry Potter}

O primeiro livro da franquia Harry Potter foi lançado pela autora J.K Rowling em 1997, alcançando sucesso expressivo no começo dos anos 2000. Até 2007 foram lançados, no total, sete livros, cada um com o lançamento posterior do filme correspondente, à exceção do último livro, que foi dividido nos filmes Harry Potter e as relíquias da morte, parte 1 e 2, encerrando a série em 2011. Até o lançamento deste último filme, aliás, a série já contabilizava mais de 400 milhões de livros vendidos em 69 idiomas e bilheterias mundiais superiores aos seis bilhões de dólares ${ }^{15}$. Desde que alcançou o grande público, formou-se uma geração de espectadores que cresceram junto com os personagens da história que, entre os livros e filmes, durou 14 anos.

Apesar de a própria J.K. Rowling admitir que estes personagens sejam "tão britânicos” (BORELI, 2007) e ter exigido, em princípio, um elenco totalmente britânico para os filmes ${ }^{16}$, há uma pluralidade de público que denota a universalidade a que remete a história. Os filmes, aliás, até mesmo pelo produto midiático que são, conseguem alcançar um público ainda maior, o que se confirmou no bem-sucedido caso de Harry Potter, visto que a série nos cinemas, que durou de 2001 a 2011, se tornou a maior bilheteria da história, sendo superada nos EUA somente três anos depois, com a franquia de filmes da Marvel $^{17}$. Além do sucesso de público, os filmes também receberam ao total 12 indicações ao Oscar, em categorias predominantemente técnicas, não tendo ganho, no entanto, nenhuma estatueta ${ }^{18}$.

\section{Resumo da história de Harry Potter e a câmara secreta}

A história do livro começa com Harry Potter após seu primeiro ano na Escola de Magia e Bruxaria de Hogwarts, sofrendo com o descaso e maus tratos de seus tios

\footnotetext{
15 Ver Os números mágicos de Harry Potter. Disponível em: <http://veja.abril.com.br/noticia/entretenimento/os-numeros-magicos-de-harry-potter/>. Acesso em: 20 ago. 2015.

16 Ver Harry Potter and the Philosopher's Stone. Disponível em: <http://www.theguardian.com/film/2001/nov/16/jkjoannekathleenrowling>. Acesso em: 19 ago. 2014.

${ }^{17}$ Ver Marvel supera “Harry Potter” como a franquia de maior sucesso nos EUA. Disponível em: $<$ http://omelete.uol.com.br/marvel-comics/cinema/marvel-supera-harry-potter-como-franquia-demaior-bilheteria-do-cinema/\#.U_v8ofldXpI>. Acesso em: 19 ago. 2014.
}

18 Ver “Harry Potter” e o “estranho” caso de desprezo do Oscar. Disponível em: $<$ http://cultura.estadao.com.br/noticias/cinema,harry-potter-e-o-estranho-caso-de-desprezo-dooscar,855633>. Acesso em: 27 abr. 2016. 
durante as férias, até que amigos da escola os resgatam de lá para que passe o resto do período de férias com eles.

Mesmo contra a vontade de seus tios, Harry volta para o seu segundo ano em Hogwarts com seus melhores amigos, Rony Weasley e Hermione Granger, e está empolgado com seus treinos de quadribol ${ }^{19}$. No entanto, Harry também volta a conviver com bruxos com os quais não tem bom relacionamento ao longo de toda trama, como o estudante Draco Malfoy, que se mostra arrogante e esnobe.

\section{Situação social}

Os estudantes da Escola de Magia e Bruxaria de Hogwarts são divididos em quatro casas que disputam entre si a taça das casas de quadribol, o esporte mais famoso do mundo bruxo. Entre estas casas estão a Grifinória, onde se encontram os protagonistas Harry, Rony e Hermione, e Sonserina, onde se encontra o rival de Harry na escola, o personagem Draco. Este último, de família rica e totalmente formada por bruxos ao longo da história, humilha os personagens Rony, de família pobre, e Hermione, de família formada por bruxos e pessoas sem poderes mágicos, os chamados “trouxas”, sendo, assim, uma mestiça:

Rony e Hermione vinham atravessando o gramado para ver o que estava acontecendo.

— Que é que está havendo? — perguntou Rony a Harry. — Por que vocês não estão jogando? E que é que ele está fazendo aqui?

Olhava para Draco, reparando nas vestes de Quadribol com as cores da Sonserina que o garoto usava.

- Sou o novo apanhador da Sonserina, Weasley — disse Draco, presunçoso. O pessoal aqui está admirando as vassouras que meu pai comprou para o nosso time.

Rony olhou, boquiaberto, as sete magníficas vassouras diante dele.

— Boas, não são? - disse Draco com a voz macia. - Mas quem sabe o time da Grifinória pode levantar um ourinho e comprar vassouras novas, também. Você podia fazer uma rifa dessas Cleansweep ${ }^{20}$; imagino que um museu talvez queira comprá-las.

O time da Sonserina dava gargalhadas.

- Pelo menos ninguém do time da Grifinória teve de pagar para entrar — disse Hermione com aspereza. - Entraram por puro talento.

O ar presunçoso de Draco pareceu oscilar. - Ninguém pediu sua opinião, sua sujeitinha de sangue ruim. — xingou ele.

\footnotetext{
${ }^{19}$ Na história de Harry Potter, o quadribol é uma espécie de futebol americano jogado por bruxos em suas vassouras com quatro diferentes bolas.

${ }^{20}$ Marca de vassoura que alguns bruxos utilizam em jogos de quadribol. No caso, a vassoura à qual Draco se refere é um modelo já ultrapassado de vassoura Cleansweep.
} 
(ROWLING, 2000, pp. 87-88)

De acordo com Garcez e Ostermann (2013, p. 264), à luz de Goffman, a situação em uma interação “emerge a qualquer momento em que dois ou mais indivíduos se encontram na presença imediata um do outro e dura até que a última pessoa tenha se retirado". Neste caso, a situação exposta é o encontro dos alunos da casa Grifinória que chegam ao campo para o treino e se deparam com o time da casa Sonserina para treinar no mesmo local, no mesmo horário.

O cenário, de acordo com a Sociolinguística Interacional, é o espaço delimitado do ambiente, “definido pelos participantes como socialmente distintos de outros espaços no qual se desenrolam os eventos e as atividades de fala” (Ibid., p. 259). Neste caso, trata-se do campo de quadribol da Escola de Magia e Bruxaria de Hogwarts, um espaço social específico onde treinam o esporte que abre possibilidades a rivalidades que acabam por interferir no relacionamento dos personagens.

Em tal cenário se desenvolve o evento que é a "definição social da atividade de fala que se desenvolve na situação” (Ibid., p. 261). No caso exposto, o evento se define a partir da conversa entre os estudantes que treinam quadribol pela casa Grifinória e os estudantes que treinam quadribol pela casa Sonserina. Já a atividade de fala, segundo Garcez e Ostermann apud Garcez (2013, p. 259), é “a unidade básica de interação socialmente relevante em termos da qual o significado é avaliado”. No caso trata-se, portanto, da fala do personagem Draco. Logo, é nessa atividade de fala que é transmitido o significado do diálogo: demonstrar a relação de preconceito presente na interação do personagem Draco com os demais participantes do encontro (Harry, Rony e Hermione). Nota-se que é a postura de um indivíduo em relação o outro, assim sendo, um reflexo das questões apresentadas pelas relações de alteridade, que caracteriza o preconceito apresentado.

Para a compreensão de tais fatores, chega-se à definição de enquadre, que se refere à “definição, com base em elementos de sinalização na fala em interação, quanto ao que está acontecendo em uma interação, sem a qual nenhuma elocução (ou movimento ou gesto) pode ser interpretada” (GARCEZ e OSTERMANN, 2013, p. 260). No diálogo entre os personagens, tal interação ocorre em função da rivalidade entre eles e o preconceito enunciado pelo personagem Draco. Este assume uma postura superior em relação aos demais colegas da escola, o que é observado como sendo o alinhamento na fala em interação. Segundo Goffman (2013, p. 113), 
"alinhamento, ou porte, ou posicionamento, ou postura, ou projeção pessoal do participante”. Assim, nota-se que o alinhamento é o modo como o personagem se posiciona na história em relação ao interlocutor.

Tais relações ocorrem em um determinado contexto, que é o "ambiente de significação que é interacionalmente constituído mediante o que as pessoas estão fazendo a cada instante em termos de onde e quando elas fazem o que fazem" (GARCEZ e OSTERMANN, 2013, p. 259). No caso estudado, o contexto é um ambiente de preconceito social, a partir da fala do personagem Draco, direcionada ao personagem Rony, e racismo, a partir da fala do personagem Draco, direcionada à personagem Hermione. Ressalta-se, aqui, que a fala racista é direcionada a uma personagem branca, o que pode abrir precedentes para uma posterior discussão sobre o protagonismo nas discussões sobre determinadas formas de preconceito em narrativas ficcionais.

Nota-se, portanto, que aos efeitos já comprovados no contato de jovens com a história da obra Harry Potter se dá através da identificação. De acordo com Ortiz e Harwood (2007) apud Vezalli et al (2015), corroborados pela teoria social cognitiva de Bandura (1997 e 2002) apud Vezalli et al (2015), o público pode vir a aprender determinados comportamentos quando estes são representados por outras pessoas que lhe tenham relevância, como, por exemplo, personagens de diferentes contextos midiáticos.

Além disso, a teoria defende que as pessoas tendem a alinhar sua forma de pensar com a de personagens da mídia quando se identificam com estes. Nos estudos de Vezzali et al (2015), se testou a identificação através da contraposição entre o personagem Harry Potter, que representa o que é positivo, e o vilão da história, Lord Voldemort, que representa o que é negativo. Porém, a identificação com personagens que representem algo de positivo ou de negativo pode ser observada se considerarmos outros personagens com a mesmas características dentro da narrativa.

Considerando o exemplo dado à luz do conceito de hexis educativa, percebese que é dada ao público a "possibilidade de pensar”, conforme a fala já citada aqui de Sodré (2013), fornecendo o contato com os lados opostos de uma relação dos personagens com o outro, para que haja a tomada de consciência sobre qual lado é o correto a escolher. Nessa possibilidade de escolha entre os diferentes lados está a liberdade proposta na hexis. Assim, a sociolinguística interacional se torna metodologia pertinente para análise uma vez que tenha como foco, no caso, o 
fenômeno da interação de um personagem com o outro, permitindo verificar cada elemento das falas que determinam qual personagem é positivo em contraposição ao personagem que é negativo.

\section{CONSIDERAÇÕES}

É essencial a compreensão das relações de alteridade e de como estas tem papel na questão do preconceito, para a enunciação de uma prática educativa e reflexiva na narrativa da série Harry Potter, utilizada neste estudo pelo grande alcance que possui. Na história contada na série, as interações entre os personagens são essenciais para compreender tais relações de alteridade e o preconceito destas decorrente, visto que as ações ali são muitas vezes motivadas pelo "saber automático” de determinados personagens sobre outros.

A história contada também remete a choques culturais que, na estrutura ficcional, acabam por levar à reflexão de questões que se apresentam na sociedade, pontuando, principalmente nas relações de alteridade entre os protagonistas, a importância de saber lidar com as diferenças e ter uma atitude tolerante com o outro, uma vez que este representa o diferente. Isto pode abrir possibilidades educativas para a reflexão sobre o preconceito.

A obra Harry Potter se apresenta como possibilidade educativa de abordagem da discussão sobre as relações de alteridade e preconceito junto aos jovens nas escolas, pois engloba livros e filmes de grande alcance com o público, que está em idade escolar, e que chamam a atenção pelas similaridades das situações vividas também pelos personagens neste ambiente.

Não se pode afirmar, porém, que a trama de Harry Potter promova, por si só, mudanças positivas na sociedade. No entanto, certos elementos são utilizados de forma recorrente na narrativa, de modo a pontuar quais são os personagens bons e maus. Assim, se estabelece a identificação do público com os personagens que estariam agindo de forma correta. É neste sentido que atua a hexis educativa, permitindo uma nova abordagem junto aos jovens sobre questões sociais relevantes para o próprio convívio entre eles, bem como para pensarem a sociedade em que estão inseridos e agirem da forma mais correta diante dela.

Ressalta-se que, a partir de uma experiência caracterizada pela hexis educativa, há maior possibilidade de uma compreensão plena de questões sociais e da cidadania, uma vez que não se atém a um modelo de ensino que determine regras a 
serem seguidas, mas mostra aos jovens - no caso de Harry Potter, através das relações de alteridade -, tanto a postura de personagens que reforçam preconceitos quanto daqueles que se posicionam contra tal atitude. Logo, o público pode passar a ter uma postura contra o preconceito por escolha, mediante a identificação com um determinado personagem que o leve a entender como agir diante da questão.

Nota-se que aí está o potencial educativo da obra. Afinal, como bem afirma Sodré (2013), educação é processo. O educar deve produzir reflexão e transformação social, e não apenas ser uma imposição de valores, ainda que corretos.

[...] [Educação] não é algo que se confine no mero adestramento para a eternização de valores estabelecidos (a pura e simples transmissão de um passado) ou para o que se a ordem do grupo julga estritamente necessário, já que em sua radicalidade eticocultural é principalmente uma viagem rumo ao contingente, ou seja, a um outro ethos possível, embora incerto. Em outras palavras, não apenas o viável de agora, mas o possível de amanhã. Na possibilidade de outros modos de produzir e pensar, eclodem as mudanças, emerge o novo, afirma-se o propriamente humano como manifestação de um senão determinado em bases absolutas - portanto, como a exigência de uma preparação permanente do si mesmo - e preparam-se as bases de transformação coerente da ordem social. (Ibid., p. 87)

No processo de expor aos jovens os valores necessários à sua reflexão, a análise sociolinguística permite notar a importância da palavra em uso na narrativa, para pontuar os elementos que remetem às relações de alteridade e preconceito. Além disso, uma vez que se trata de um estudo de interações entre personagens, a Sociolinguística Interacional permite compreender que certas características próprias da interação são importantes nos diálogos, de modo a contrapor diferentes posturas em relação à temática do preconceito junto ao público da série Harry Potter.

Contudo, o exemplo aqui utilizado está presente em um livro da série, sendo que a Sociolinguística Interacional permite analisar, também, gestos, silêncios e outros fatores que, associados ao uso da fala, estão presentes na interação. Logo, uma análise não só mais profunda dos livros, quanto também dos filmes, se faz interessante à pesquisa aqui proposta.

Do mesmo modo, a Sociolinguística Interacional fornece ferramentas para propor uma análise em sala de aula de interações entre os alunos. Ela pode ser utilizada em uma proposta de atividade, como a reprodução, neste ambiente, por meio de livros, filmes, ou mesmo em atividades cênicas, de diálogos da obra Harry Potter, acompanhados de observação das atividades de fala e identificação dos alunos, do que é pontuado na história que propicie a reflexão sobre a questão do 
preconceito. Tais possibilidades de pesquisa abrem, portanto, precedentes para estudos posteriores nas áreas de Comunicação e de Educação.

\section{REFERÊNCIAS}

ARENDT, Hannah. A condição Humana. Rio de Janeiro: Forense Universitária, 2007.

BAKHTIN, Mikhail. Marxismo e filosofia da linguagem. 12 ed. São Paulo: Hucitec, 2006.

Estética da criação verbal. 2 ed. São Paulo: Martins Fontes, 1997.

BARBOSA, Marialva Carlos. Percursos do olhar. Niterói: EdUFF, 2007.

BORELI, Silvia Helena Simões. Harry Potter: Conexões Midiaticas, Produção e Circulação, Cenários Urbanos e Juvenis. In: Anais do VII Encontro dos Núcleos de Pesquisa em Comunicação - NP Comunicação e Culturas Urbanas, 2007. Disponível em: <http://www.intercom.org.br/papers/nacionais/2007/resumos/R10631.pdf > . Acesso em: 16 jul. 2015.

CONCEIÇÃO, Edilene Maria da, e AMITRANO, Geórgia Cristina. A relação entre a identidade narrativa de Paul Ricouer e a identidade política de Hannah Arendt.

Revista de Estudos Filosóficos. São João Del Rei, n. 6, p. 65-74, 2011. Disponível em: $\quad<$ http://www.ufsj.edu.br/portal2-repositorio/File/revistaestudosfilosoficos/art4 _rev6.pdf $>$. Acesso em: 03 jun. 2015.

HALL, Stuart. A identidade cultural na pós-modernidade. 11 ed. Rio de Janeiro: DP\&A, 2006.

HELLER, Agnes. O cotidiano e a história. 6 ed. São Paulo: Paz e Terra, 2000.

JENKINS, Henry. Cultura da convergência. 2 ed. São Paulo: Aleph, 2009.

MORIN, Edgar. Antropologia da liberdade. In: Dossiê Ética e o Futuro da Cultura. Revista Margem, n. 9. Tradução de Marcelo Cid e revisão de Edgard de Assis Carvalho. São Paulo: FAPESP e Edu, 1999.

PORTO, Adriana Corrêa Silva e GONÇALVES, Fernando. Considerações sobre o culto à imagem em Game of Thrones: experiência estética e recepção. [S.l.]. Revista Geminis, 2013. Disponível em: <http://www.revistageminis.ufscar.br/ index.php/geminis/article/view/133>. Acesso em: 03 jun. 2015.

RIBEIRO, Branca Telles e GARCEZ, Pedro M. (Orgs.) Sociolinguística interacional. 2 ed. São Paulo: Loyola, 2013.

ROWLING, J. K. Harry Potter e a câmara secreta. Rio de Janeiro: Rocco, 2000.

SODRÉ, Muniz. Antropológica do espelho. Uma teoria da comunicação linear e em rede. 8 ed. Petrópolis: Vozes, 2013.

Invenção do Contemporâneo. A ignorância da diversidade. 49'53'’. TV Cultura, 2011. Disponível em: <http://www.cpflcultura.com.br/wp/2011/04/05/aignorancia-da-diversidade-\%E2\%80\%93-muniz-sodre/>. Acesso em: 25 set. 2014.

VEZALLI, Loris et al. The greatest magic of Harry Potter: reducing prejudice. Journal of Applied Social Psychology. n. 45. Reggio Emilia: 2015. Disponível em: 
<http://onlinelibrary.wiley.com/doi/10.1111/jasp.12279/pdf>. Acesso em: 22 jan. 2016.

\title{
OS AUTORES
}

Milena de Azeredo Pacheco Venancio é mestranda em Mídia e Cotidiano na Universidade Federal Fluminense, com graduação em Publicidade e Propaganda pela mesma instituição. Pós-graduanda em Marketing e Comunicação Empresarial pela Universidade Veiga de Almeida, com experiência na área de Marketing e Comunicação. É integrante do grupo de pesquisa educ@midia.com da Universidade Federal Fluminense

\begin{abstract}
Alexandre Farbiarz possui doutorado em Design pela Pontifícia Universidade Católica do Rio de Janeiro (2007), mestrado em Educação e Linguagem pela Universidade de São Paulo (2001) e mestrado em Design pela Pontifícia Universidade Católica do Rio de Janeiro (2000). Coordena grupo de pesquisa Educação para as Mídias em Comunicação - educ@midia.com. É professor associado do departamento de Comunicação Social da Universidade Federal Fluminense, integrando o corpo docente Permanente do Programa de Pós-Graduação em Mídia e Cotidiano e professor do Curso de Comunicação Social/Jornalismo. Tem experiência nas áreas de Comunicação, Design e Educação, com ênfase em relações discursivas em ambientes virtuais de aprendizagem.
\end{abstract}

